\title{
SIGNPUDDLE: O USO DO SISTEMA SIGNWRITING NA PRODUÇÃO TEXTUAL EM LÍNGUA BRASILEIRA DE SINAIS ***
}

\section{SIGNPUDDLE: THE USE OF THE SIGNWRITING SYSTEM IN TEXTUAL PRODUCTION IN BRAZILIAN SIGN LANGUAGE}

RESUMO: O presente artigo apresenta os aspectos essenciais do SignPuddle, software desenvolvido por Steve Slevinski, para produção textual, transcrição e registro da forma escrita das línguas de sinais para o sistema SignWriting. Essa ferramenta possibilita a produção de materiais científicos, bem como outros materiais em Língua Brasileira de Sinais (Libras). O propósito deste artigo é apontar as especificidades da ferramenta por meio de uma análise descritiva baseada em uma pesquisa realizada, em um colégio bilíngue de surdos, com o uso de textos transcritos de Libras para SignWriting através do SignPuddle. As novas tecnologias da informação e comunicação em conjunto com o SignPuddle e SignWriting contribuem para estudos linguísticos, produções textuais em línguas de sinais e, principalmente para a educação de surdos.

PALAVRAS-CHAVE: Libras; surdos; produção textual; sistema SignWriting.

ABSTRACT: This paper presents the essential aspects of SignPuddle, software developed by Steve Slevinski, for textual production, transcription and registration of the written form of sign languages for the SignWriting system. This tool enables the production of scientific materials as well as other materials in Brazilian Sign Language (Libras). The purpose of this article is to point out the specificities of the tool through a descriptive analysis based on a research carried out in a bilingual college for deaf people using texts translated from Portuguese to Libras/SignWriting through SignPuddle. New information and communication technologies in combination with SignPuddle and SignWriting contribute to language studies, textual productions, especially, the education of the Deaf.

KEYWORDS: Libras; Deaf; textual production; SignWriting system.

\footnotetext{
${ }^{1}$ Doutoranda em Linguística pela Universidade Federal de Santa Catarina (UFSC) e Professora do Departamento de Educação da Universidade Tecnológica Federal do Paraná (UTFPR - Câmpus Apucarana).E-mail: danielebozoli@utfpr.edu.br

${ }^{2}$ Doutora em Informática na Educação pela Universidade Federal do Rio Grande do Sul (UFRGS) e Professora do Departamento de Libras da Universidade Federal de Santa Catarina (UFSC). E-mail: stumpfmarianne@gmail.com
} 


\section{Introdução}

Com o passar dos anos, a tecnologia vem progredindo e aprimorando as formas de comunicação. Os softwares podem ser utilizados como meios de escrever, transcrever, traduzir e editar textos. No caso da Língua Brasileira de Sinais (Libras) há um software que permite escrever os sinais da Libras, assim, não é mais apenas uma língua falada através de gestos, mas que também pode ser escrita.

A Libras é reconhecida como meio legal de comunicação e expressão pela Lei $n^{o} 10.436$ (BRASIL, 2002) e o Decreto $n^{\circ} 5.625$ (BRASIL, 2005) regulamenta as ações para consolidação do uso da Libras, como a inserção da Libras nos currículos acadêmicos, a garantia dos direitos dos surdos como cidadãos e a formação de professores de Libras.

A tecnologia aplicada ao processamento de Libras possui ferramentas para a produção de escrita textual através de novas tecnologias da informação e comunicação. Entre os softwares existentes há um, cujas especificidades atendem o sistema SignWriting e possibilitam o registro de forma escrita das características linguísticas das línguas de sinais.

\section{Fundamentos de SignWriting}

Conforme Aguiar e Chaibue (2015), surgiram outros sistemas para a escrita de sinais antes do SignWriting, nome dado pela inventora estadunidense Valerie Sutton, ao sistema. Sutton desenvolveu o sistema SignWriting, em 1974, na Universidade de Copenhaque, Dinamarca. 
O SignWriting iniciou-se com base nos passos de dança escritos por Sutton na época em que era coreógrafa (BARRETO; BARRETO, 2015). Essa escrita, denominada DanceWriting, foi descoberta pelos pesquisadores de língua de sinais dinamarquesa (DTS - Dansktegnspro) que procuravam uma maneira de passar a DTS para a escrita. Logo, contataram Sutton, que se propôs a participar da ideia.

Em virtude das inovações tecnológicas e processos linguísticos, o SignWriting atravessou o universo da escrita por mais de 40 anos. A grande disseminação das informações em relação ao sistema SignWriting decorre pelo fato de haver páginas na internet (SignWriting For Sign Languages), desenvolvidas por Sutton e visitadas por usuários do mundo todo. O sistema SignWriting não foi a única invenção de Sutton, ela também criou o Sutton Movement Writing, um sistema de escrita global que constitui o Alfabeto Internacional de Escrita de Movimentos (IMWA - International Movement Writing Alphabet), podendo ser digitado ou manuscrito.

De acordo com Sutton (2011), o IMWA é utilizado para registrar todos os gestos humanos, comparado com o Alfabeto Fonético Internacional (AFI) para as línguas orais. Compreendendo melhor, o AFI registra os detalhes das línguas baseadas em sons, enquanto o IMWA registra os das línguas/linguagens baseadas em movimentos. Por ora, o IMWA concentra cinco sistemas:

a. SignWriting - anota as línguas de sinais;

b. DanceWriting - anota os passos e coreografia de danças;

c. MimeWriting - anota as expressões corporais e fisionômicas; 
d. SportsWriting - anota os passos de patinação de gelo, ginástica e skate;

e. MovementWriting - serve para análise de gestos.

Em respeito às línguas visuais-espaciais, Stumpf (2005), e Barreto e Barreto (2015) afirmam que o SignWriting se enquadra adequadamente aos parâmetros fonológicos das línguas de sinais na escrita, tais como configurações de mãos, orientações da mão, movimentos, locações, expressões faciais e corporais. Por este motivo, o SignWriting se torna a cada dia a forma padrão mundial de escrita de sinais. Milhares de escritores, tanto surdos quanto ouvintes, espalhados por mais de 60 países registram suas respectivas línguas de sinais através deste sistema.

\section{Plataformas de SignPuddle}

Segundo Sutton (2011), o SignPuddle é um dos softwares específicos para o sistema SignWriting, desenvolvido pelo designer de softwares, Steve Slevinski e concebido a partir de 2004. Desde então, Slevinski tem desempenhado no aperfeiçoamento do mesmo e desenvolvido outros programas relacionados ao SignWriting. Atualmente, o SignPuddle se encontra em diferentes plataformas:

a. SignPuddle Online - é uma plataforma requer uso de internet que permite acessar dicionários de diversas línguas de sinais escritas e inserir sinalários escritos pelos usuários. 
b. PersonalPuddle - é um SignPuddle para uso pessoal a ser instalado nos computadores Mac e Windows. Os usuários podem utiliza-lo sem internet. Com a conexão de internet, o PersonalPuddle interage com o SignPuddle Online.

c. PocketPuddle - é um SignPuddle portátil, ou seja, os usuários podem carregar consigo um pendrive USB que vem com o PersonalPuddle totalmente instalado. É ideal para quem acessa diversos computadores e os dados podem ser salvos diretamente no pendrive USB sem depender da conexão de internet.

d. Private WebPuddle - é uma área exclusiva no SignPuddle Online com senha para usuários. O usuário pode armazenar dados pessoais e com a configuração personalizada, é possível incluir outros usuários para a interação em grupo.

e. SignPuddle WorkStation - é uma estação de trabalho de SignPuddle, voltada para uso profissional específico e criação de produtos. O uso do computador requer capacidade de processamento de cálculos e gráficos superior aos comuns.

f. SignPuddle Servers - são servidores de SignPuddle executados através de redes de computadores, para a realização de projetos privados. Proporcionam os mesmos mecanismos de Private WebPuddle e SignPuddle WorkStation, além de fornecer um servidor de e-mails, sincronização de dicionários, atualizações de códigos e suporte técnico.

O SignPuddle Online passou por diversas atualizações devido à sua ampla utilização, a versão 1.0 possuía ferramentas online como consulta de dicionários, criador e editor de sinais escritos e pesquisa de símbolos ou

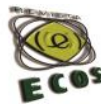


explicações. O SignPuddle versão 2.0, que se encontra disponível atualmente, teve o intuito de aperfeiçoar todas as funcionalidades da versão anterior com maior simplificação e clareza, dando suporte com um único clique e hospedagem de textos escritos (STUMPF, 2005; BARTH, 2008).

O SignPuddle versão 3.0 está em fase de desenvolvimento, sendo dividido em dois projetos, porém cooperativos: o front-end para a interação de usuários e o back-end para a manipulação de dados. Compreendendo melhor, o primeiro será destinado aos usuários comuns, podendo visualizar e editar informações com uma interface moderna em uma variedade de plataformas como computadores e dispositivos móveis, enquanto o segundo será direcionado aos desenvolvedores externos, podendo interagir diretamente com os dados do SignPuddle e publicar novos dados de seus produtos (SLEVINSKI, 2016).

Salienta-se que o software SignPuddle emprega o Alfabeto Internacional de SignWriting (ISWA - International SignWriting Alphabet) como fonte padrão de escrita do SignWriting. A última versão atualizada, o ISWA 2010, é composta de 652 símbolos-base para escrever línguas de sinais (SUTTON, 2011).

A seguir, compreenderemos as técnicas computacionais do SignPuddle Online, para a composição de sinais escritos para a criação de textos de variados gêneros escritos, tais como carta, bilhete, pôster e entre outros. 
ISSN: $2316-3933$

Online

\subsection{Inicializando o uso do SignPuddle Online}

O uso do SignPuddle Online é gratuito e para o melhor funcionamento do mesmo, Slevinski e Sutton (2007) orientam o uso do navegador Mozilla Firefox. A interface é toda em inglês, mas pelo fato de ser intuitiva e colorida, é simples compreender as opções, como selecionar a bandeira de um país (figura 1).

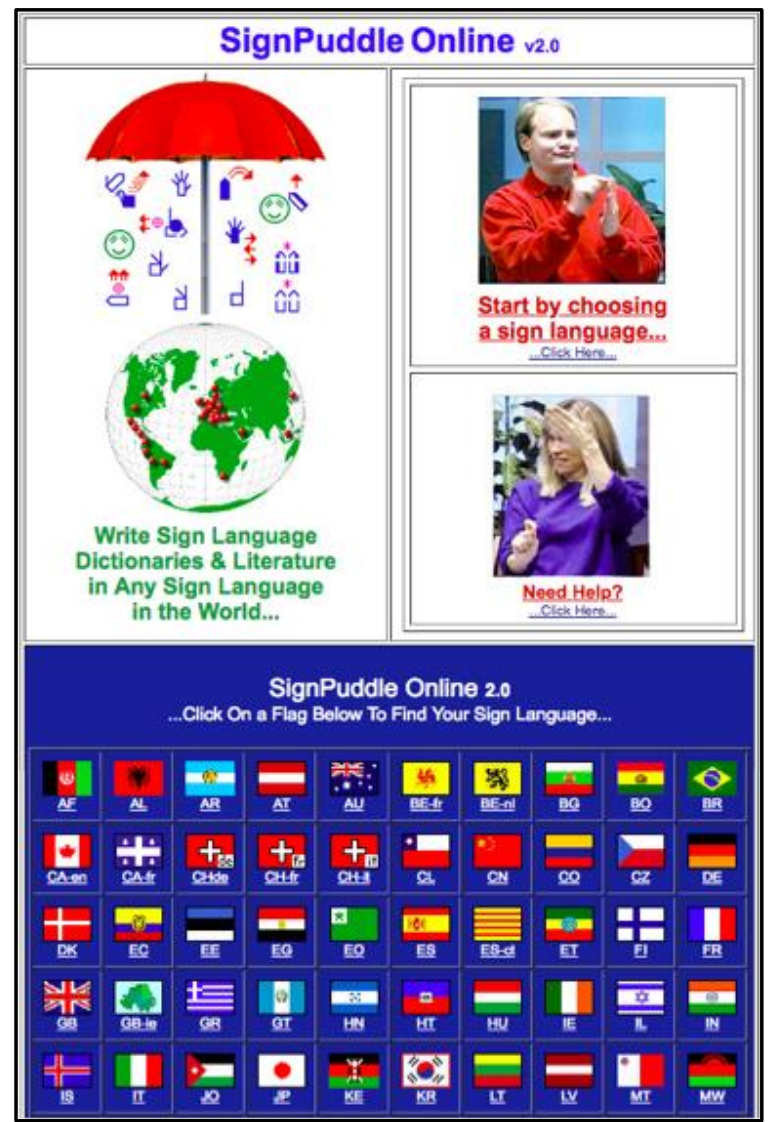

Figura 1. Interface de pré-abertura do SignPuddle Fonte: 〈http://www.signbank.org/signpuddle/>

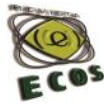


Cada país possui um dicionário de língua de sinais, uma biblioteca literária, uma enciclopédia e um manual de instruções. Neste artigo, concentramos no dicionário brasileiro. Ao clicar na bandeira brasileira o conteúdo é direcionado ao diretório de Libras (figura 2).

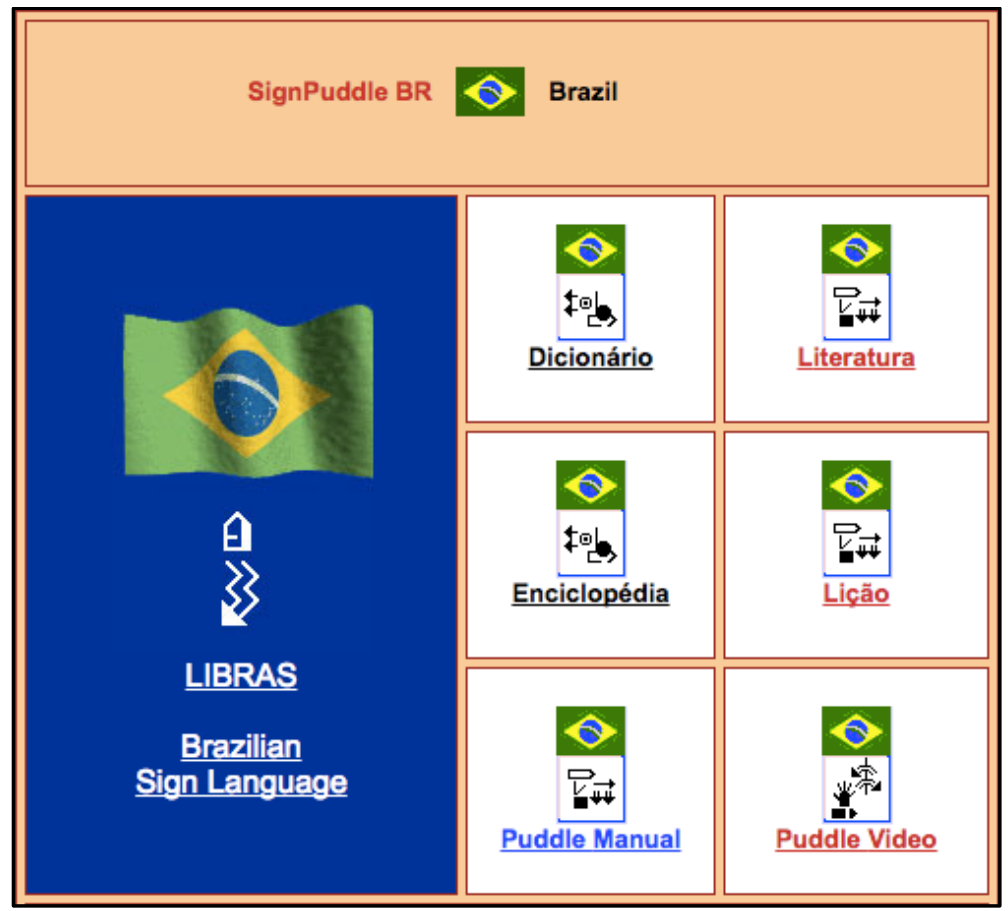

Figura 2. Diretório de Libras

Fonte: <http://www.signbank.org/signpuddle/>

A língua majoritária do Brasil, ou seja, o português toma conta a partir deste diretório. No entanto, nos dirigimos ao ícone "Dicionário" para a abertura do mesmo. 


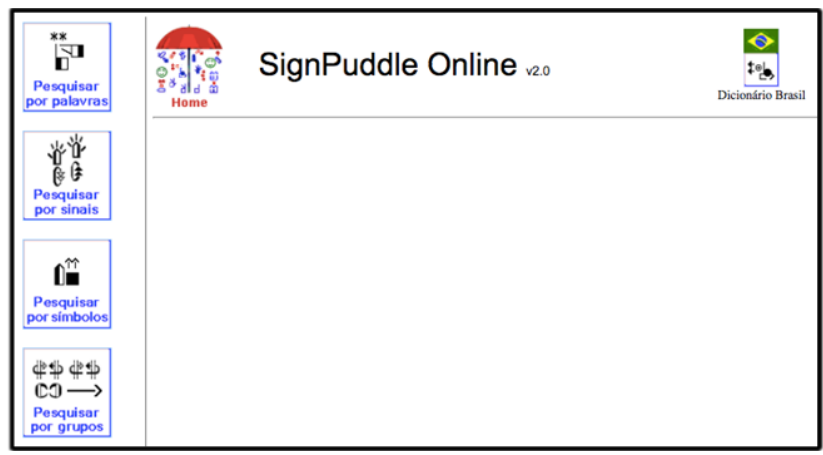

Figura 3. Interface de abertura do SignPuddle - Dicionário de Libras/Brasil

Fonte: <http://www.signbank.org/signpuddle/>

Antes de iniciar a escrita da Libras, é necessário cadastrar e logar no SignPuddle, assim será possível editar e deletar sinais inseridos no diretório posteriormente. Os usuários sem cadastro não possuem essas alternativas, ou seja, poderão inserir sinais equivocados no dicionário.

\subsection{Escrevendo línguas de sinais}

Para escrever Libras, os usuários devem dirigir-se ao editor de línguas de sinais chamado SinalCriador, que se encontra no canto esquerdo. Sua tela fica semelhante ao diagrama da figura 5.

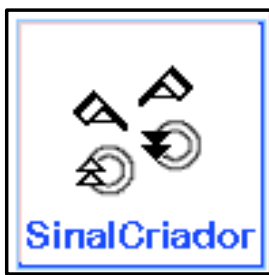

Figura 4. Ícone "SinalCriador"

Fonte: 〈http://www.signbank.org/signpuddle/>

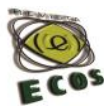


ISSN: $2316-3933$

Online

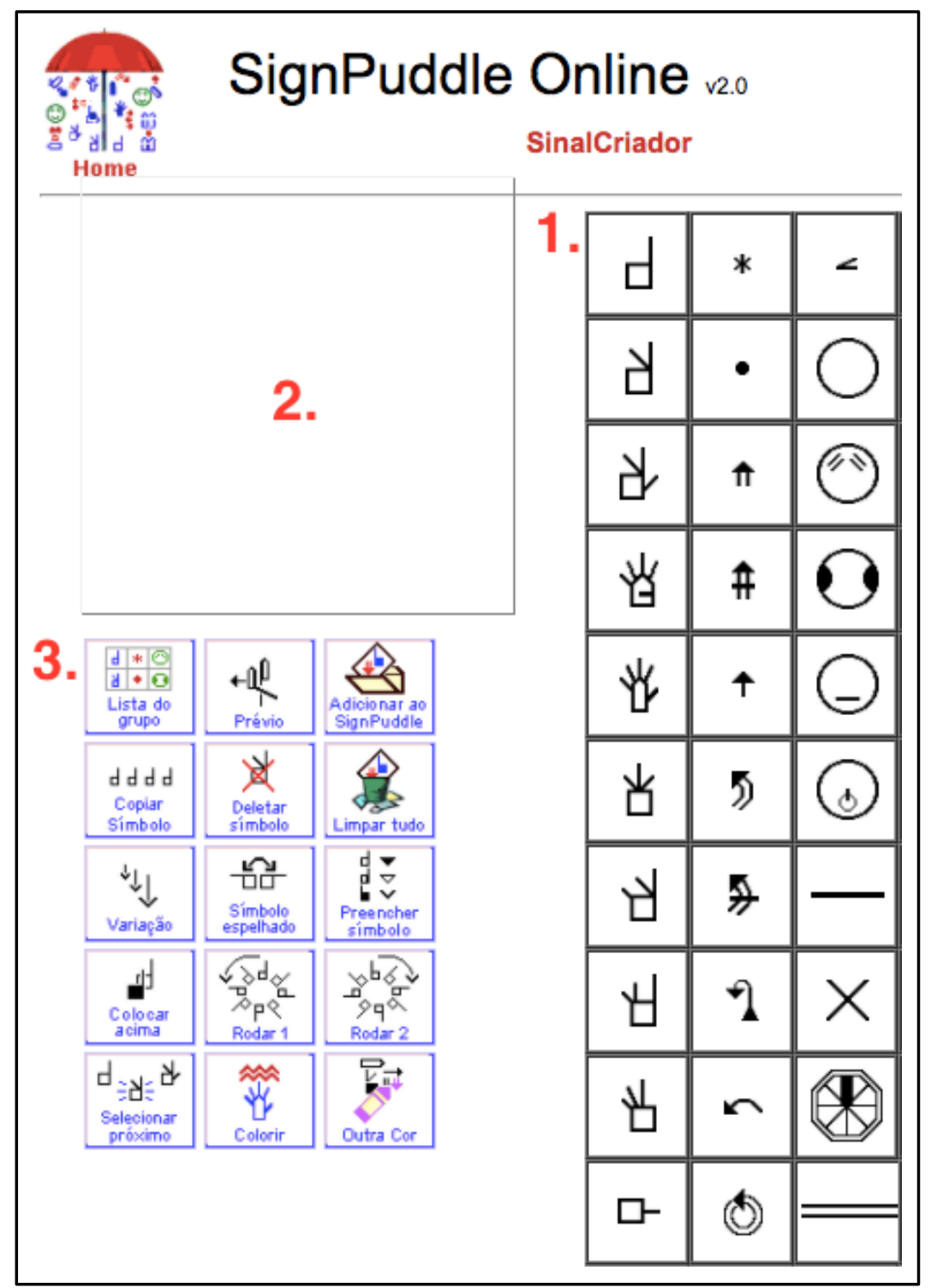

Figura 5. Design de tela do SignPuddle

Fonte: <http://www.signbank.org/signpuddle/>

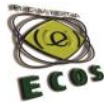


À medida que nos deslizarmos para baixo ou para o lado, o SinalCriador moverá partes na tela, para que possamos visualizar tudo. Em grandes telas de computador, o design de tela fica somente em um lugar (SLEVINSKI; SUTTON, 2007).

A seguir, serão abordadas as ferramentas do SinalCriador e suas funções, referindo-se aos números no diagrama da figura 5 .

1. Paleta de símbolos - É o conjunto de símbolos do Alfabeto Internacional de SignWriting (ISWA 2010), distribuídos em sete categorias: mãos, movimentos, dinâmica e tempo, cabeça e faces, corpo, locações detalhadas e pontuação (SUTTON, 2011). É preciso clicar sobre os símbolos para criar sinais em SignWriting. Em seguida, arrastar para a caixa de entrada.

2. Caixa de entrada - É onde a estrutura dos sinais é criada. Os símbolos da paleta devem ser arrastados para este campo. Essa técnica é chamada Drag \& Drop, ou seja, arrastar e soltar o símbolo com o mouse.

3. Botões de comando - Os botões têm as seguintes funções:

a. Lista do grupo - retorna à paleta de símbolos;

b. Prévio - retorna à camada anterior da paleta de símbolos;

c. Adicionar ao SignPuddle - insere novos sinais em um dicionário;

d. Copiar símbolo - duplica o mesmo símbolo selecionado;

e. Deletar símbolo - exclui o símbolo selecionado;

f. Limpar tudo - todos os símbolos na caixa de entrada desaparecem;

g. Variação - altera o tamanho das setas e fornece algumas formas e faces com símbolos relacionados; 
h. Símbolo espelhado - o símbolo inverte horizontalmente, da esquerda para a direita e vice-versa;

i. Preencher símbolo - altera a orientação da palma de mão, a ponta da seta, e os lados direito e esquerdo da face;

j. Colocar acima - o símbolo selecionado se move na frente ou sobre o outro símbolo;

k. Rodar 1 - o símbolo gira no sentido anti-horário;

1. Rodar 2 - o símbolo gira no sentido horário;

m. Selecionar próximo - seleciona outro símbolo disponível na caixa de entrada para podermos fazer alterações nele;

n. Colorir - colore os símbolos em cores padrão do SignWriting (azul, rosa, vermelho e verde);

o. Outra cor - com o símbolo selecionado, podemos colorilo conforme a paleta de diferentes cores.

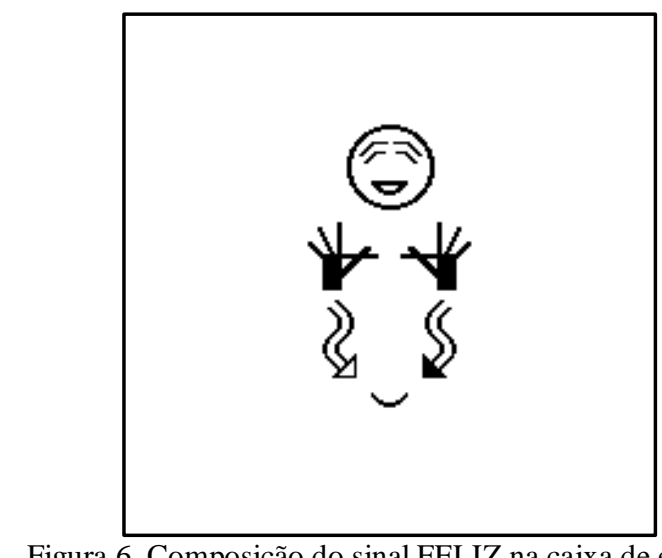

Figura 6. Composição do sinal FELIZ na caixa de entrada Fonte: 〈http://www.signbank.org/signpuddle/> 
Após terminar a composição de um sinal, por exemplo o sinal de feliz na caixa de entrada do SignPuddle (figura 6), é necessário clicar no botão de comando "Adicionar ao SignPuddle". O mesmo nos direciona à página de termos e títulos, onde é solicitado um ou até doze nomes, em campos separados, em português. De acordo com as experiências, é aconselhável escrever termos em letras minúsculas e sinônimos para facilitar as futuras consultas e traduções.

\begin{tabular}{|l|l|l||}
\hline Termos e Títulos: & feliz & \\
\hline & & \\
\hline
\end{tabular}

Figura 7. Exemplo de informações na página de termos e títulos Fonte: <http://www.signbank.org/signpuddle/> 
Além disso, é possível adicionar outras informações como "Texto" para descrição do sinal e "Fonte" para escrever o nome do criador ou da referência da fonte. Essas informações são opcionais e ao concluir, deve-se clicar no botão "Adicionar" para que a composição da figura 6 seja inserida e registrada no dicionário do SignPuddle.

\subsection{Editando línguas de sinais}

No dia a dia da revisão de línguas de sinais em SignWriting, percebemos que alguns erros, sejam de ortografia ou símbolos, são comuns. Assim, após a identificação do erro é preciso corrigi-lo imediatamente, desta forma, aqueles que criarem os sinais no SignPuddle podem editar e/ou alterar os símbolos, uma vez estando cadastrado e logado no sistema.

Em relação à funcionalidade, as figuras 8 e 9 mostram a diferença entre os botões de funções para um usuário cadastrado e não cadastrado durante $\mathrm{o}$ acesso à interface.

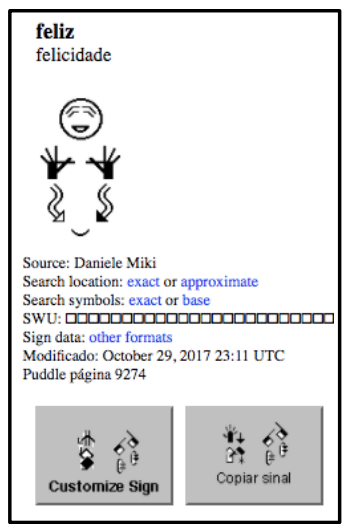

Figura 8. Botões de funções para usuário sem cadastro no SignPuddle

Fonte: <http://www.signbank.org/signpuddle/>

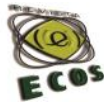




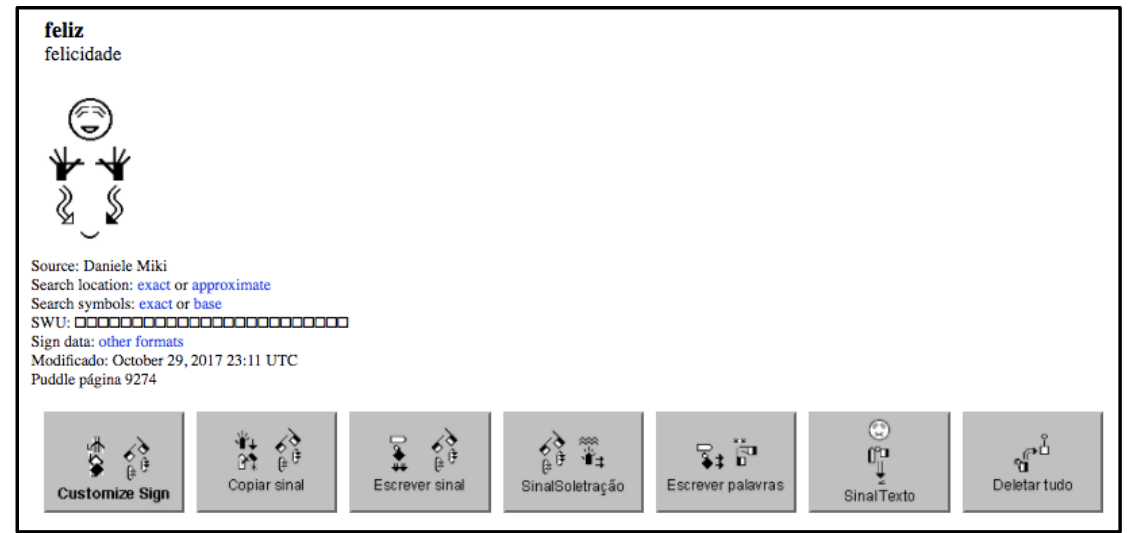

Figura 9. Botões de funções para usuário cadastrado no SignPuddle Fonte: <http://www.signbank.org/signpuddle/>

Observamos que para um usuário não cadastrado as opções são restritas e para um usuário cadastrado as opções de edição são maiores.

A seguir, apresentamos a especificação das funções da figura 11 que o SignPuddle nos fornece para a edição de línguas de sinais:

a. Customizar sinal - personaliza o sinal conforme nossas preferências, como formatar a imagem, ajustar o tamanho, colorir o sinal, manter o fundo transparente e entre outros;

b. Copiar sinal - tira cópia do sinal para outros diretórios de SignPuddle ou para reformular novos sinais;

c. Escrever sinal - edita ou altera a forma do sinal selecionado;

d. Escrever palavras - edita, apaga ou acrescenta palavras em português;

e. Deletar tudo - exclui totalmente o sinal do dicionário. 
A função mais interessante e proveitoso do SignPuddle é a customização de sinais, uma excelente ferramenta para imprimir e publicar materiais científicos, livros e dicionários em SignWriting e/ou multilíngues.

\section{Customizar}

Formato da imagem

Tamanho de sinais

Preenchimento de Sinais

Cor de Sinais

Cor de Fundo

Espaço em torno sinal

\section{SVG Refinement as PNG}

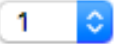

$0 \hat{\imath}$

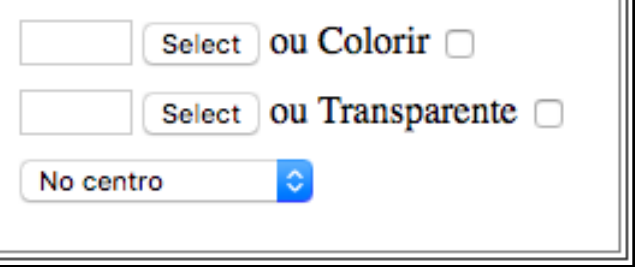

Figura 10. Exemplos de customização

Fonte: <http://www.signbank.org/signpuddle/>

Com o uso das ferramentas do SignPuddle Online, os usuários podem estruturar inúmeros sinais e adicioná-los aos dicionários, sem a necessidade de escreve-los novamente. Conforme a necessidade dos usuários, eles podem consultar os sinais inseridos no diretório de Libras e realizar transcrições de Libras para SignWriting.

\section{Produção de textos em SignWriting}

O uso e o ensino de SignWriting nas aulas de Libras é pertinente pelo fato do sistema de escrita estar diretamente relacionado com a Libras. A pesquisa foi realizada no colégio bilíngue de surdos, localizado em 
Maringá/PR, onde as aulas de SignWriting contaram com a participação de cinco alunos, entre 16 e 19 anos, usuários de Libras (BÓZOLI, 2015).

Após o conhecimento básico do sistema SignWriting, os alunos foram convidados a realizar uma leitura e interpretação dos textos referentes à disciplina de História. Os textos sobre a "Primeira Guerra Mundial" e o “Governo Juscelino Kubitschek” foram elaborados pelas próprias autoras, em razão da escassez de materiais específicos em SignWriting para a educação básica.

O software utilizado para a transcrição e produção dos textos foi o SignPuddle Online, o qual também permite copiar e colar em outros arquivos. Devido à falta de alguns sinais relacionados aos conteúdos de História no SignPuddle, foi necessário compor a escrita de novos sinais, e assim, pudemos ampliar o dicionário de Libras/SignWriting no SignPuddle - Dicionário de Libras/Brasil.

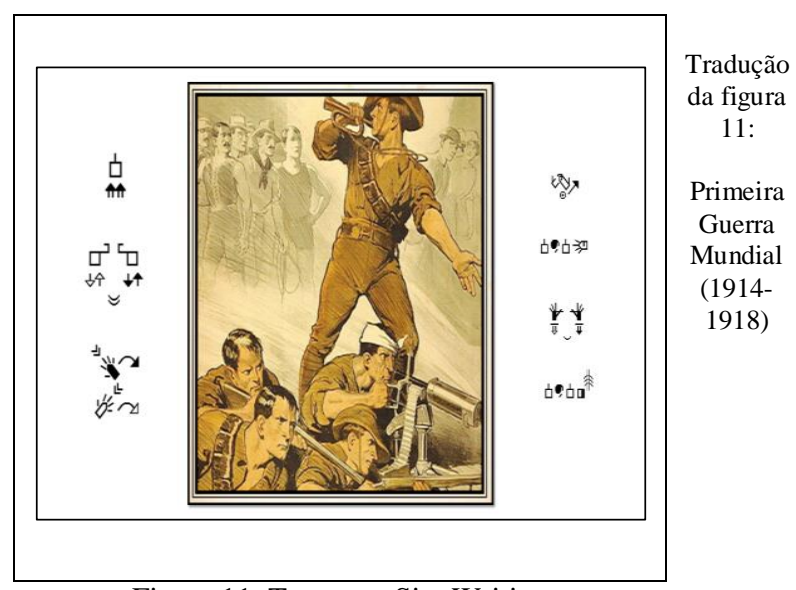

Figura 11. Texto em SignWriting Fonte: (BÓZOLI, D. M. F., 2015, p. 69) 
ISSN: $2316-3933$

Online

Programa de Pós-graduação em Estudos Literários/ UNEMAT

Programa de Pós-graduação em Linguística/ UNEMAT

Centro de Estudos e Pesquisas em Literatura

Centro de Estudos e Pesquisas em Linguagem

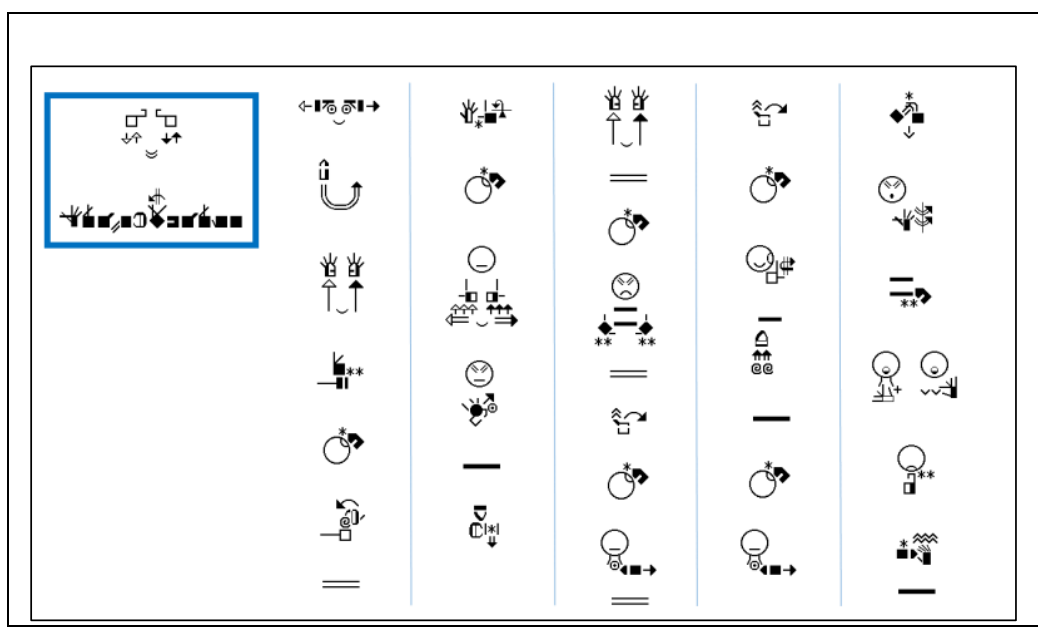

Tradução da figura 12:

A guerra de trincheiras

Trincheira era uma estratégia de guerra, com valas escavadas no solo onde os soldados escondiam-se para proteger-se e atacar os inimigos. Nelas, milhões de soldados ficaram sujeitos à fome, ao frio $\mathrm{e}$ ao medo constante da morte por bombardeios, granadas, tiros e doenças.

Figura 12. Texto em SignWriting

Fonte: (BÓZOLI, D. M. F., 2015, p. 71)

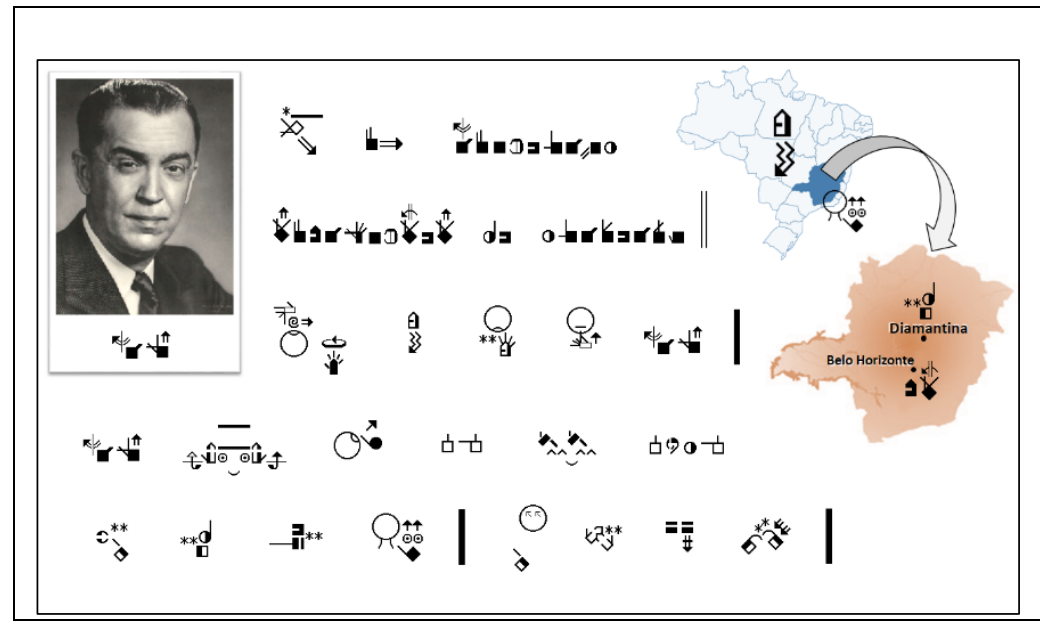

Tradução da figura 13:

Juscelino Kubitschek de Oliveira, conhecido como JK, nasceu em $\underline{12}$ de setembro de 1902 em Diamantina/MG.

Formou-se em Medicina.

Figura 13. Texto em SignWriting

Fonte: (BÓZOLI, D. M. F., 2015, p. 73)

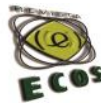




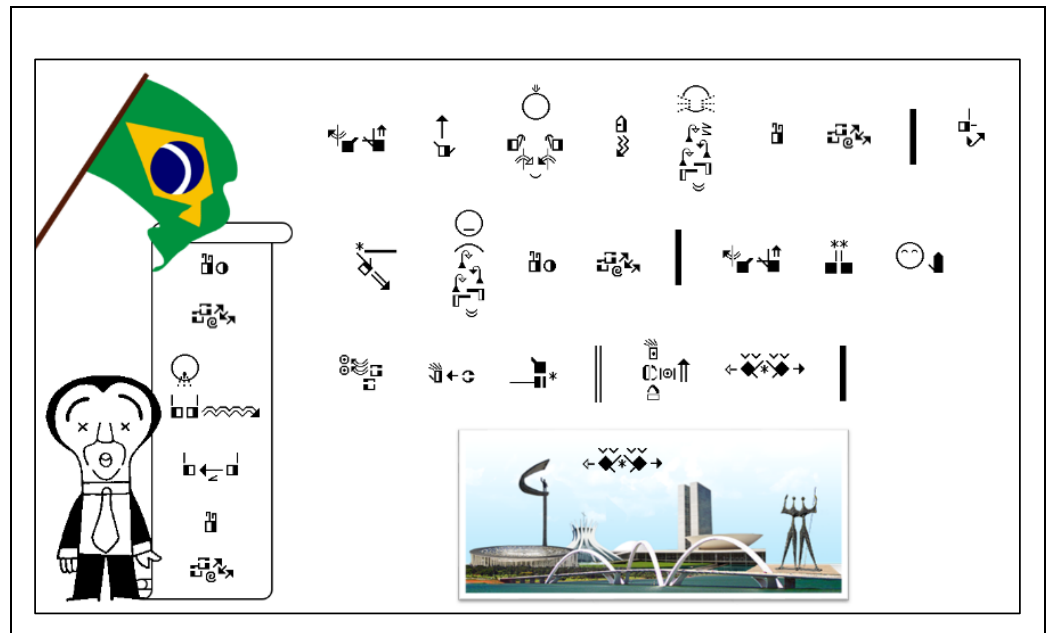

Tradução da figura 14:

A promessa dos "50 anos em 5 "

JK prometia que seu governo faria em 5 anos o que outros demorariam 50 anos. Ele também prometeu construir uma nova capital para o Brasil, longe das grandes cidades. Foi assim que surgiu Brasília no centro do país.

Figura 14. Texto em SignWriting
Fonte: (BÓZOLI, D. M. F., 2015, p. 74

Segundo Quadros e Karnopp (2004), as sentenças da Libras são distintas do ponto de vista estrutural das do português. Por isso, foi fundamental fazer uma releitura de textos sobre os temas selecionados para a tradução, além do complemento de imagens relacionadas aos acontecimentos do passado.

Nas figuras 11 e 12, os sinais escritos são dispostos no sentido vertical, da esquerda para a direita, enquanto nas figuras 13 e 14, os sinais apresentam-se no sentido horizontal, de cima para baixo. A escrita da Libras pelo sistema SignWriting, alinhada verticalmente, permite uma leitura mais rápida (BARRETO; BARRETO, 2015).

Em nosso estudo, as produções escritas em SignWriting foram transcritas a partir da Libras, com o propósito de favorecer a apropriação conceitual em conteúdos específicos da disciplina de História, para que os 
alunos surdos, que não possuíam domínio total da interpretação de textos em português, pudessem compreender melhor os conteúdos trabalhados.

\section{Considerações finais}

Os sistemas de escrita para as línguas de sinais criados antes do SignWriting não se progrediram devido à complexidade dos símbolos na escrita. O SignWriting apresenta-se como o sistema mais adequado para escrever os parâmetros fonológicos, referidos anteriormente, da Libras.

A universalidade do sistema SignWriting sucede em razão da formulação do Alfabeto Internacional de SignWriting (ISWA 2010), cujo trabalho foi iniciado a partir de 2004 com a parceria entre Valerie Sutton e Steve Slevinski. O ISWA 2010 permite registrar as características linguísticas de todas línguas de sinais do mundo.

O SignPuddle Online é um banco de dados interativo e é comum encontrarmos no diretório de Libras vários sinais diferentes, seja em virtude da regionalidade ou de pequenos erros ortográficos. Infelizmente, não há controle no armazenamento dos sinalários no SignPuddle Online, o que ocasiona em muitos sinais repetidos e equivocados estruturalmente.

A transcrição de textos através do sistema SignWriting possibilita que os usuários de Libras agreguem conhecimento aprendendo com a nova ferramenta, dessa forma, o SignWriting serve de apoio para o desenvolvimento dos aprendizes de Libras.

Apesar da disponibilidade de recursos tecnológicos, o uso do SignWriting no ensino, em escolas bilíngues de surdos, ainda é muito 
desafiador. Os motivos para essas dificuldades são a morosidade na produção de material transcrito e o quadro restrito de profissionais qualificados na área.

Assim, compreendemos que as escolas bilíngues devem buscar meios para propiciar aos usuários esse conhecimento, uma vez que o sistema SignWriting representa uma oportunidade real de ganho linguístico e intelectual para a comunidade surda. Concomitantemente com as novas tecnologias da informação e comunicação, o SignPuddle e SignWriting podem ser excelentes ferramentas para os estudos linguísticos, para traduções das línguas de sinais e principalmente, na educação de surdos.

\section{Referências}

AGUIAR, T. C.; CHAIBUE, K. Histórico das Escritas de Línguas de Sinais. In: Revista Virtual de Cultura Surda. 2015. Edição nº 15. Disponível em <http://editora-arara-azul.com.br/site/revista_edicoes> Acesso em 28. fev. 2018.

BARRETO, M; BARRETO, R. Escrita de sinais sem mistérios. 2 ed. Salvador: Libras Escrita, 2015.

BARTH, C. Construção da leitura escrita em línguas de sinais de crianças surdas em ambientes digitais. 2008. 141 f. Dissertação (Mestrado em Educação). Faculdade de Educação, Universidade Federal do Rio Grande do Sul.

BÓZOLI, D. M. F. 2015. 188 f. Dissertação (Mestrado em Educação). Centro de Ciências Humanas, Letras e Artes, Universidade Estadual de Maringá. 
BRASIL. Lei n ${ }^{o} 10.436$, de 24 de abril de 2002. Dispõe sobre a Língua Brasileira de Sinais - Libras e dá outras providências. Brasília: Diário Oficial da $\quad$ União, 2002. Disponível em <http://www.planalto.gov.br/ccivil_03/Leis/2002/L10436.htm> Acesso em 28 fev. 2018.

BRASIL. Decreto $n^{\circ} 5.626$, de 22 de dezembro de 2005. Regulamenta a Lei $n^{\circ} 10.436$, de 24 de abril de 2002, que dispõe sobre a Língua Brasileira de Sinais - Libras, e o art. 18 da Lei n ${ }^{\circ} 10.098$, de 19 de dezembro de 2000. Brasília: Diário Oficial da União: 2005. Disponível em <http://www.planalto.gov.br/ccivil_03/_ato20042006/2005/decreto/d5626.htm> Acesso em 28 fev. 2018.

Mozilla Firefox. Disponível em <https://www.mozilla.org > Acesso em 28 fev. 2018.

QUADROS, R. M; KARNOPP, L. B. Língua de sinais brasileira: estudos linguísticos. Porto Alegre: Artmed, 2004.

SignPuddle Online. Disponível em <http://www.signbank.org/signpuddle/> Acesso em 28 fev. 2018.

SignWriting For Sign Languages. Disponível em <http://www.signwriting.org/> Acesso em 28 fev. 2018.

SLEVINSKI, S. E. SignPuddle 3: Front \& Back. 2016. Disponível em <http://www.signwriting.org/symposium/presentation0062.html> Acesso em 28 fev. 2018.

SLEVINSKI, S.; SUTTON, V. SignPuddle Reference Manual 1.5. 2007. Disponível em <http://www.signwriting.org/archive/docs5/sw0485-USSignPuddle15Manual.pdf> Acesso em 28 fev. 2018. 
ISSN: 2316-3933

Online

STUMPF, M. R. Aprendizagem de escrita de língua de sinais pelo sistema de SignWriting: Línguas de sinais no papel e no computador. 2005. $330 \mathrm{f}$. Tese (Doutorado em Informática na Educação). Faculdade de Educação, Universidade Federal do Rio Grande do Sul.

SUTTON, V. The SignWriting Alphabet: read and write any sign language in the world. 2011. Disponível em <http://www.signwriting.org/archive/docs7/sw0636_SignWriting_Alphab et_Manual_2010.pdf> Acesso em 28 fev. 2018. 